\title{
Isolamento de Salmonella sp e Staphylococcus aureus no processo do abate suíno como subsídio ao sistema de Análise de Perigos e Pontos Críticos de Controle - APPCC ${ }^{1}$
}

\author{
Emilia do Socorro C. de Lima ${ }^{2}$, Paulo Sérgio de A. Pinto ${ }^{2}$, José L. dos Santos ${ }^{2}$, \\ Maria Cristina D. Vanetti ${ }^{3}$, Paula D. Bevilacqua ${ }^{2}$, Laerte P. de Almeida ${ }^{4}$, Mayara S. \\ Pinto $^{2}$ e Francesca S. Dias ${ }^{2}$
}

\begin{abstract}
Lima E.S.C., Pinto P.S.A., Santos J.L., Vanetti M.C.D., Bevilacqua P.D., Almeida L.P., Pinto M.S. \& Dias F.S. 2004. [Isolation of Salmonella sp and Staphylococcus aureus at swine slaughtering as subsidy for HACCP, the Hazard Analysis and Critical Control Point system.] Isolamento de Salmonella sp e Staphylococcus aureus no processo do abate suíno como subsídio ao sistema de Análise de Perigos e Pontos Críticos de Controle - APPCC. Pesquisa Veterinária Brasileira 24(4):185-190. Depto Veterinária, Universidade Federal de Viçosa, 36571-000 Viçosa, Minas Gerais, Brazil. E-mail: pintopsa@ufv.br

This study was done to evaluate the superficial contamination of swine carcasses by Salmonella sp and Staphylococcus aureus, the identification of microbiological hazards in different segments of the processing line, and critical control points (CCPs), through the quantification of risks. A total of 120 surface swabbing carcasses were collected in a slaughterhouse: after the scalding/dehairing (point A), before evisceration (B), after evisceration and splitting $(\mathrm{C})$, and after 24 hours of refrigeration (D). Salmonella sp and S. aureus were isolated from $14(11.7 \%)$ carcasses. No statistical difference between the points studied was observed. The number of S. aureus isolated was between 1.2 and $1.5 \log \mathrm{UFC} / \mathrm{cm}^{2}$. It was concluded that the risks observed were the same for both microorganisms.

INDEX TERMS: Salmonella sp, Staphylococcus aureus, swine carcass, slaughterhouse, HACCP.
\end{abstract}

RESUMO.- O presente estudo foi realizado para avaliar a presença de Salmonella sp e o número de Staphylococcus aureus na superfície de carcaças suínas e caracterizar os perigos microbiológicos em diferentes etapas do abate e pontos críticos de controle (PCCs), através da quantificação de riscos (odds ratio). Um total de 120 esfregaços superficiais de carcaça suína foi coletado em um matadouro-frigorífico, após o escaldamento/ depilação (ponto A), antes da evisceração (B), após evisceração e serragem da carcaça (C) e após 24 horas de refrigeração (D). Salmonella sp foi encontrada com uma frequiência média de 11,7\% (14) nas carcaças, enquanto o número de $S$. aureus variou entre

\footnotetext{
${ }^{1}$ Recebido em 29 de agosto de 2003.

Aceito para publicação em 30 de março de 2004.

Dissertação de Mestrado em Medicina Veterinária da Universidade Federal de Viçosa (UFV).

${ }^{2}$ Depto de Veterinária, UFV, 36571-000 Viçosa, MG. *Autor para correspondência. E-mail: pintopsa@ufv.br

${ }^{3}$ Depto Microbiologia, UFV.

${ }^{4}$ Faculdade de Medicina Veterinária, UFU, Uberlândia, MG 38400-902.
}

1,2 e $1,5 \log \mathrm{UFC} / \mathrm{cm}^{2} \mathrm{em} 11,7 \%$ das carcaças amostradas, sem evidenciar diferença estatística entre os pontos A, B, C e D. Podese concluir que os riscos de contaminação por Salmonella sp e $S$. aureus foram os mesmos nas etapas do abate de suínos consideradas neste estudo.

TERMOS DE INDEXAÇÃO: Salmonella sp, Staphylococcus aureus, carcaça suína, abate, APPCC.

\section{INTRODUÇÃO}

A carne e os seus produtos têm sido freqüentemente implicados como veículos da transmissão de patógenos para humanos. Salmonella sp e Staphylococcus aureus, dentre outras bactérias patogênicas, presentes na superfície de carcaças suínas, entram na planta de abate a partir dos animais vivos e dos operários, não existindo procedimentos de inspeção especificamente direcionados para o controle desses microrganismos, apesar de estarem relacionados como principais riscos para a saúde pública (Saide-Albornoz et al. 1995, Korsak et al. 1998).

Em países industrializados, 80 a $90 \%$ dos casos de salmonelose estão associados com o consumo de produtos de 
origem animal e 15\% com a carne suína (Berends et al. 1998). Segundo Borch et al. (1996) e Berends et al. (1997), Salmonella sp destaca-se como a principal bactéria patogênica incorporada na linha de abate pelo próprio suíno. O risco dessa contaminação está dimensionado por uma probabilidade 3,5 vezes maior para suínos portadores das mesmas em comparação aos não portadores (odds ratio 3,5). Por isso, Berends et al. (1996) consideraram importante o controle, sobretudo da Salmonella sp, em etapas anteriores ao abate, incluindo o transporte e o sistema de criação.

O número de Salmonella sp na superfície da carcaça de suínos pode ser reduzido com a adoção dos procedimentos adequados de abate, tais como escaldamento individual, remoção cuidadosa dos intestinos e a descontaminação após o abate (Biemuller et al. 1973, Berends et al. 1997).

Thorberg \& Engvall (2001) relataram que os processos particularmente envolvidos no risco de contaminação por Salmonella sp no abate de suínos são a evisceração e a toalete, mas o escaldamento e a divisão da carcaça também podem introduzir microrganismos que resultam em uma maior contaminação ao fim da linha do abate.

As fezes e os linfonodos de suínos são uma importante origem das contaminações das carcaças nas etapas de abate por Salmonella sp. Kasbohrer et al. (2000), na Alemanha, isolaram Salmonella sp em 3,7\% das amostras fecais, em 3,3\% dos linfonodos e em $4,7 \%$ dos esfregaços das carcaças suínas.

S. aureus também tem um importante papel entre os microrganismos causadores de intoxicações alimentares. Bean \& Griffin (1990) mostraram que cerca de $41 \%$ de todas as intoxicações estafilocócicas nos Estados Unidos, entre 1973 e 1987, ocorreram após o consumo de carne e produtos cárneos; sendo que o produto suíno foi a origem da infecção em $38,7 \%$ desses casos. S. aureus enterotoxigênico pode ser encontrado em número e locais diferentes do corpo, como narinas e garganta, tanto do ser humano como dos animais (Borch et al. 1996). Essa bactéria também pode colonizar a pele e membranas mucosas e pode estar transitoriamente no trato intestinal (Hansson 2001).

Nas plantas de processamento de carne, Salmonella sp e $S$. aureus podem ser freqüentemente identificados nas mãos dos manipuladores, sobre as superfícies de trabalho e equipamentos, demonstrando que a contaminação cruzada entre carcaças pode ocorrer, revelando a necessidade de limpar e sanitizar o ambiente de abate (Schraft et al. 1992).

A possibilidade de contaminação microbiana da superfície da carcaça de suínos em um matadouro é ampla, tanto por bactérias deterioradoras quanto por patogênicas. $O$ processo de abate inclui algumas operações nas quais o número de bactérias pode diminuir, mas não inclui nenhuma etapa capaz de eliminálas totalmente (Rivas et al. 2000). Borch et al. (1996) e Berends et al. (1997) observaram que as fases de escaldamento, depilação e evisceração destacam-se por promover o aumento do número da contaminação bacteriana.

Os fatores de risco da Salmonella sp em suínos têm sido intensivamente investigados, com relação ao rebanho, ao transporte, aos matadouros e ao comércio (Gill \& Bryant 1993, Berends et al. 1996, Schlosser et al. 2000). Diferentes estudos têm demonstrado a incidência de Salmonella sp em suínos abatidos através da análise das fezes e das carcaças (Oosterom et al. 1985, Hald et al. 1999, Kasbohrer et al. 2000). No Brasil as pesquisas mais recentes envolveram análises de amostras do conteúdo cecal, linfonodos e/ou tonsilas de suínos e demonstraram uma prevalência de Salmonella sp de 12 a 34\% (Costa et al. 1972, Zebral \& Freitas 1974, Langenegger et al. 1983, Lázaro et al. 1997).

O sistema de Análise de Perigos e Ponto Crítico de Controle (APPCC) se apóia em vários princípios, destacando-se como os mais importantes, a identificação de perigos e de pontos críticos de controle (PCCs) em consonância com o estabelecimento dos procedimentos de monitorização desses PCCs, com vistas ao controle dos perigos, durante a produção do alimento. Dentre os recursos de implementação do sistema APPCC, Carr et al. (1998) sugerem os testes microbiológicos da pesquisa de Salmonella sp e contagem de $S$. aureus, para monitorar a contaminação microbiana de carcaças de suínos.

A legislação estabelecida pelo do Ministério da Agricultura, Pecuária e Abastecimento (MAPA) determinou, desde 1998, a implantação paulatina do sistema APPCC nas indústrias de produtos de origem animal. No Brasil, existem 131 matadouros de suínos com o Serviço de Inspeção Federal, dos quais 16 estão localizados no Estado de Minas Gerais. Entretanto, somente alguns já têm o sistema APPCC implantado ou estão em fase de implantação, principalmente os estabelecimentos exportadores; revelando assim a necessidade de pesquisas que subsidiem a implantação desse programa de garantia de qualidade nos estabelecimentos de abate de suínos.

O presente trabalho teve por objetivos avaliar a contaminação superficial de carcaças suínas quanto à presença de Salmonella sp e ao número de Staphylococcus aureus, e identificar os pontos críticos de controle no processo de abate de suínos.

\section{MATERIAL E MÉTODOS}

\section{Amostragem e delineamento experimental}

Esta pesquisa foi desenvolvida em um matadouro-frigorífico de suínos, localizado no Estado de Minas Gerais. No processo de abate, 120 carcaças foram analisadas em quatro etapas (pontos) diferentes do fluxograma (Fig. 1): imediatamente após a fase de escaldamento/ depilação (ponto A), imediatamente antes da evisceração (ponto B), após evisceração e serragem das carcaças (ponto C) e após 24 horas de refrigeração (ponto $D$ ).

Em cada etapa do abate, 30 carcaças suínas foram amostradas aleatoriamente. Em cada carcaça foi analisada uma área total de $140 \mathrm{~cm}^{2}$, subdividida em sete subáreas de $20 \mathrm{~cm}^{2}$, assim definidas: nas regiões externas dos dois pernis, das duas paletas, das duas regiões médias das costelas e do ventre, quando a carcaça ainda não tinha sido eviscerada; após a abertura da carcaça a região externa do ventre foi substituída pela região interna mediana de uma das últimas costelas. Essas subáreas foram delimitadas por moldes estéreis com área interna livre de $20 \mathrm{~cm}^{2}$, onde foram realizados esfregaços superficiais com o auxílio de swabs estéreis, com $5 \mathrm{~mm}$ de diâmetro, previamente umedecidos em solução salina a $0,85 \%$ estéril. Em cada subárea foram utilizados dois swabs, que foram girados sobre a superfície, um no sentido horizontal e outro no sentido vertical. Em seguida, com o descarte da haste de madeira os swabs foram acondicionados em sacos plásticos estéreis tipo "Wirl-Parker".

O material foi conduzido imediatamente após a coleta, sob refrigeração, ao laboratório para as análises microbiológicas. 

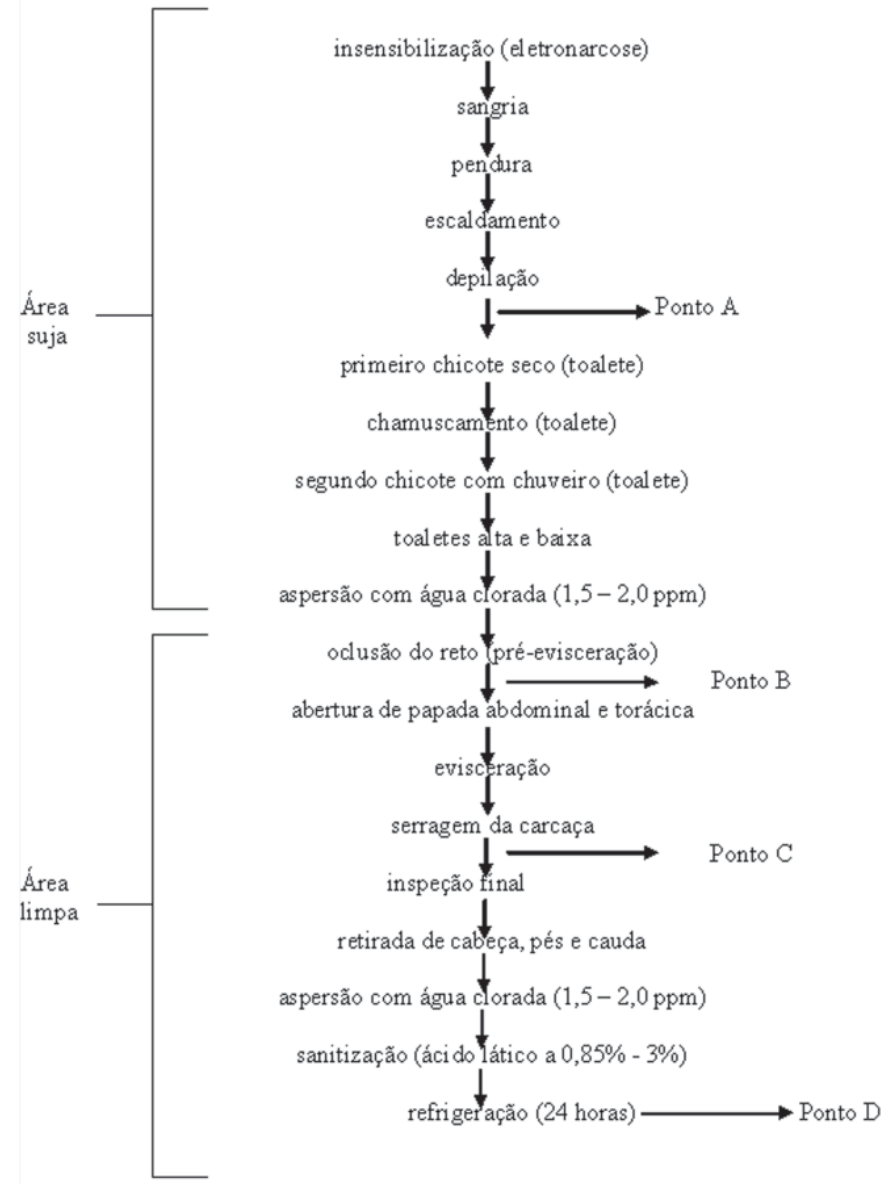

Fig. 1. Fluxograma de matadouro-frigorífico de suínos e pontos de coleta.

\section{Ensaios microbiológicos}

No mesmo dia da coleta os swabs foram individualmente colocados em $140 \mathrm{ml}$ de água peptonada tamponada a $0,1 \%$ e homogeneizados, durante 1 minuto, em homogenizador peristáltico (Stomacher).

A pesquisa de Salmonella sp foi realizada segundo o International Comission on Microbiological Specification for Food (ICMSF), a partir de $25 \mathrm{~mL}$ do homogenato. Para o isolamento e identificação de Salmonella sp a amostra foi inicialmente pré-enriquecida em Caldo Lactosado, seguida do enriquecimento seletivo em Caldo Tetrationato (TT) e Selenito Cistina (SC), observado-se os períodos de incubação e temperaturas recomendados. O isolamento foi feito em Ágar Verde Brilhante (VB), Xilose Lisina Desoxicolato (XLD) e Bismuto Sulfito (BS). As colônias típicas passaram por uma identificação bioquímica preliminar com ágar inclinado Tríplice Açúcar Ferro (TSI) e Lisina Ferro (LIA). Os isolados que apresentaram reações típicas foram submetidos à análise bioquímica complementar com os testes de hidrólise da uréia, fermentação de carboidratos (dulcitol, lactose e sacarose), $\mathrm{IMV}_{\mathrm{i}} \mathrm{C}$ (indol, vermelho de metila, Voges-Proskauer e citrato), degradação do malonato e descarboxilação da lisina. Complementarmente, realizaram-se os testes sorológicos com anti-soros polivalentes somático $(\mathrm{O})$ e flagelar $(\mathrm{H})$ de referência (Probac).

A contagem de $S$. aureus foi realizada segundo o ICMSF. A partir do homogenato, $1 \mathrm{ml}$ foi destinado para o preparo das diluições $10^{-1}$, $10^{-2}$ e $10^{-3}$. Alíquotas de $0,1 \mathrm{ml}$ das diferentes diluições foram plaqueadas, em duplicada, por espalhamento na superfície do ágar Baird-Parker. As placas contendo entre 20 e 200 UFC foram selecionadas para a contagem de colônias típicas; pelo menos cinco UFC típicas foram confirmadas pela coloração de Gram e repicadas em caldo infusão cérebro e coração (BHI). A partir desse subcultivo foram conduzidos os testes de coagulase e de DNAse. Os resultados foram expressos em $\mathrm{UFC} / \mathrm{cm}^{2}$ e obtidos em função do número de colônias típicas contadas, diluição inoculada e porcentagem de colônias confirmadas no teste de DNAse, e transformados para $\log \mathrm{UFC} / \mathrm{cm}^{2}$.

\section{Análise estatística}

Inicialmente, calculou-se a média e o desvio padrão, através do programa BioEstat (Ayres et al. 2000) para a contagem de $S$. aureus por ponto de coleta. Adotou-se o Teste de Newman-Keuls $(\mathrm{p}<0,05)$ para análise das possíveis interações entre as médias dos diferentes pontos de controle nas etapas de abate.

Para Salmonella sp e S. aureus, também calculou-se a porcentagem de positivos, com a expectativa de analisar pelo teste do $\mathrm{X}^{2}$ a significância estatística das diferenças entre as frequiências das referidas bactérias nas quatro etapas de abate estudadas.

\section{RESULTADOS E DISCUSSÃO}

A freqüiência de isolamento de Salmonella sp neste estudo em carcaças suínas foi de 11,7\% (Quadro 1). Embora o percentual de detecção desse patógeno nas quatro etapas da linha de abate tenha variado de 6,7 a $16,7 \%$, não foi verificada diferença estatisticamente significante entre esses valores. Dessa forma, o fator de risco (odds ratio) não foi quantificado, ou seja, o risco de ocorrer esse patógeno foi estatisticamente o mesmo, nas diferentes etapas do avaliadas no processamento da carne suína.

O resultado da presença de Salmonella sp em carcaças suínas é variado e são registrados valores tão baixos como $1,4 \%$ (Swanemburg et al. 2001), até valores próximos de 13\% (Oosterom et al. 1985) e mais elevados como 27\% (Korsak et al. 1998), 29\% (Epling et al. 1993) e 30\% (Berends et al. 1997).

A porcentagem média dessa enterobactéria em amostras do trato intestinal tem sido de $21 \%$ (Oosterom et al. 1985); entre $1,5 \%$ e $18 \%$ nos cortes do diafragma e nas fezes, respectivamente (Mafu et al. 1989); 15\%, 17\% e 22,2\%, em tonsilas, conjunto fígado-diafragma e fezes de suínos, respectivamente (Borch et al. 1996); média de 10,9\% em amostras de tonsilas, linfonodos mesentéricos, conteúdo retal e swabs do fígado, língua e carcaças (Swanenburg et al. 2001). No Brasil, as pesquisas mais recentes que analisaram a contaminação de suínos com Salmonella sp,

Quadro 1. Frequiência de isolamentos de Salmonella sp, em $25 \mathrm{~cm}^{2}$ de carcaça suína em diferentes etapas dos abate

\begin{tabular}{ccc}
\hline $\begin{array}{c}\text { Pontos da } \\
\text { coleta }\end{array}$ & $\begin{array}{c}\mathrm{N}^{\circ} \text { de } \\
\text { amostras }\end{array}$ & $\begin{array}{c}\mathrm{N}^{\mathrm{O}} \text { de } \\
\text { isolados }\end{array}$ \\
\hline A & 30 & 3 \\
B & 30 & 2 \\
C & 30 & 5 \\
D & 30 & 4 \\
Total & 120 & 14 \\
& \\
A = imediatamente após o escaldamento/depilação. \\
B = imediatamente antes da evisceração. \\
C = após a evisceração e serragem das carcaças. \\
D = após 24 horas de refrigeração.
\end{tabular}


demonstraram uma prevalência de 12,6\% no Pará (Langenegger et al. 1983), 13,7\% em Salvador (Costa et al. 1972), 20,3\% (Zebral \& Freitas 1974) e 34,8\% (Lázaro et al. 1997) no Rio de Janeiro, em amostras do conteúdo cecal, linfonodos e/ou tonsilas. Esses resultados demonstram que a freqüência dessa bactéria na carne suína pode variar em função do tipo de amostra analisada. Entretanto, sua simples presença no alimento deve ser avaliada cuidadosamente, pois a legislação corrente exige ausência de Salmonella sp em $25 \mathrm{~g}$ ou ml (Brasil 1997).

É provável que a temperatura da água de escaldamento do estabelecimento avaliado, mantida a $62^{\circ} \mathrm{C}$, tenha evitado uma maior detecção de Salmonella sp no ponto A (Quadro 1). Hald et al. (1999) recomendaram manter essa temperatura maior que $60^{\circ} \mathrm{C}$ para evitar contaminação bacteriana das carcaças, pois consideram a presença de Salmonella sp nesse ambiente um fator de risco.

A presença de Salmonella sp em $10 \%$ das amostras coletadas no ponto A pode ser atribuída ao processo de depilação. Conforme Gill \& Bryant (1993) todas as carcaças suínas que passam pelas depiladeiras são contaminadas com microrganismos fecais, dentre eles Salmonella sp. A higiene da máquina de depilar é laboriosa e constitui um fator de grande importância na frequiência de Salmonella sp em carcaças suínas (Biemuller et al. 1973, Thorberg \& Engvall 2001).

Embora não tenha ocorrido aumento significativo na recuperação de Salmonella sp das amostras entre os pontos B e C, a maior frequiência de Salmonella sp encontrada no ponto $\mathrm{C}$ pode ser atribuída ao processo de evisceração, pois esse procedimento tem sido um dos principais fatores de risco para a contaminação de carcaças com enteropatógenos nessa fase. Letellier et al. (1999) demonstraram, em amostras do ceco de suínos, uma prevalência de $5,2 \%$ de Salmonella sp imediatamente após a evisceração. Por isso, a validação da técnica de evisceração é importante e deve ser feita através de repetidos exames microbiológicos para microrganismos indicadores. Segundo Berends et al. (1997), a toalete pré-evisceração geralmente contribui com 5-15\% da contaminação da carcaça com Salmonella sp e o restante, 85-95\%, é atribuído à evisceração (55-90\%) e demais operações posteriores (5-30\%).

A oclusão com saco plástico e a liberação manual ou mecânica do reto, realizadas no estabelecimento estudado, podem ter contribuído para que a freqüência de Salmonella sp no ponto C não fosse mais alta. Esses procedimentos, segundo Borch et al. (1996), reduzem expressivamente a contaminação microbiana de carcaças de $10 \%$ para $0,8 \%$. Berends et al. (1998), também afirmaram que a oclusão do reto evita $75 \%$ da contaminação da carcaça com Salmonella sp.

O processo de aspersão de ácido lático na carcaça, seguido de refrigeração, não contribuiu para a redução da contaminação por Salmonella sp (ponto D), pois esse patógeno ainda foi encontrado em uma freqüência de $13,3 \%$ nessas amostras. Resultados diferentes foram apresentados por Biemuller et al. (1973), que encontraram Salmonella sp em apenas 1,2\% das amostras tratadas com ácido lático e concluíram que a sua aspersão nas carcaças reduziu essa contaminação.

Algumas hipóteses podem ser consideradas para argumentar essa freqüência de Salmonella sp nas quatro etapas estuda- das. Nesse sentido, o estado de suíno portador deve ser investigado, pois Swanemburg et al. (2001) confirmaram que o abate de rebanhos livres e infectados por Salmonella sp leva a contaminação cruzada durante o abate. Isto seria evitado se os rebanhos fossem separados durante o transporte, nos currais de espera e as carcaças nas câmaras de refrigeração. Da mesma forma, o transporte e repouso dos suínos realizados sob ótimas condições de higiene e conforto podem reduzir o número de suínos portadores, mas somente cerca de $10 \%$ do acréscimo previsível de Salmonella sp (Berends et al. 1998). Ademais, Miller et al. (1997) concluíram que o repouso dos suínos durante período inferior a quatro horas no matadouro predispõe à ruptura das vísceras, pois esse curto período de repouso não é suficiente para que o intestino seja esvaziado, indicando que o perigo de contaminação, sobretudo por enterobactérias, esteja sempre presente nestas condições.

A contagem de Staphylococcus. aureus nas carcaças de suínos variou de 1,2 a $1,5 \log \mathrm{UFC} / \mathrm{cm}^{2}$ e não foram detectadas diferenças entre as quatro etapas do abate avaliadas (Quadro 2). Sendo assim, o fator de risco não foi quantificado e a probabilidade de

Quadro 2. Contagem de Staphylococcus aureus em carcaças suínas $(n=120)$ nas diferentes etapas do abate

$\begin{array}{cr}\text { Pontos da coleta } & \text { Contagem }(\log \text { UFC/ } \\ \text { A } & 1,23 \pm 0,77_{\mathrm{Y}} \\ \text { B } & 1,32 \pm 0,81_{\mathrm{Y}} \\ \text { C } & 1,39 \pm 1,03_{\mathrm{Y}} \\ \text { D } & 1,15 \pm 0,64_{\mathrm{Y}}\end{array}$

\footnotetext{
* Média \pm desvio padrão. Médias seguidas das mesmas letras não são estatisticamente significantes $(\mathrm{p}<0,05)$.

$\mathrm{A}=$ imediatamente após escaldamento e depilação.

$\mathrm{B}=$ imediatamente antes da evisceração.

$\mathrm{C}=$ após evisceração e serragem das carcaças.

$\mathrm{D}=$ após 24 horas de refrigeração.
}

ocorrer esse patógeno foi estatisticamente a mesma nas diferentes etapas do processamento da carne suína. Essa contagem é considerada baixa em carcaça suína, quando comparada com os achados de Borch et al. (1996), que encontraram uma variação entre 1 a $6 \log \mathrm{UFC} / \mathrm{cm}^{2}$. Mesmo assim, tal contaminação deve ser considerada importante, pois pode ocorrer multiplicação desse patógeno durante as etapas do abate, e por isso, caracterizar-se como um parâmetro de risco para a saúde pública.

A frequiência de $S$. aureus pode ser considerada alta (Quadro 3), apesar de que não foi observado um aumento significativo na contagem desse patógeno no sentido do escaldamento/depilação até a refrigeração. Mesmo assim, houve um acréscimo na frequência de $S$. aureus entre os pontos A e B de 10 para 16,7\%, que provavelmente pode ter ocorrido por influência dos operários que manipulavam as carcaças nas etapas de toaletes realizadas após o chamuscamento e antes da evisceração. Os manipuladores têm sido implicados como as possíveis fontes desse patógeno no ambiente de abate. Nos estudos de SaideAlbornoz et al. (1995), S. aureus, mesmo sendo o patógeno mais prevalente, foi encontrado em somente $7,4 \%$ das carcaças analisadas, tendo um aumento significativo do ponto de 
Quadro 3. Frequiência de isolamentos de Staphylococcus aureus em $25 \mathrm{~cm}^{2}$ de carcaça suína em diferentes etapas dos abate

\begin{tabular}{cccc}
\hline $\begin{array}{c}\text { Pontos da } \\
\text { coleta }\end{array}$ & $\begin{array}{c}\text { No }^{\text {de }} \\
\text { amostras }\end{array}$ & $\begin{array}{c}\text { Números de } \\
\text { isolados }\end{array}$ & $\%$ \\
\hline A & 30 & 3 & 10,00 \\
B & 30 & 5 & 16,70 \\
C & 30 & 4 & 13,33 \\
D & 30 & 2 & 6,70 \\
Total & 120 & 14 & 11,66
\end{tabular}

$\mathrm{A}=$ imediatamente após o escaldamento/depilação.

$\mathrm{B}=$ imediatamente antes da evisceração.

$\mathrm{C}=$ após a evisceração e serragem das carcaças.

$\mathrm{D}=$ após 24 horas de refrigeração.

chamuscamento até a refrigeração. Outros autores também mostraram um aumento de $S$. aureus isolados de carcaças analisadas durante o abate (De Wit \& Kampelmacher 1981).

A menor frequência de $S$. aureus no ponto $D$ pode ser atribuída ao processo de refrigeração que inibe a multiplicação desse patógeno a baixas temperaturas. Segundo observações de Borch et al. (1996) e Carr et al. (1998), o resfriamento rápido da carcaça suína promove uma inibição da proliferação de Staphylococcus $\mathrm{sp}$, inclusive em relação ao sistema de resfriamento convencional $\left(0^{\circ} \mathrm{C} / 24 \mathrm{~h}\right)$. Esses autores observaram ainda que a capacidade de Staphylococcus sp em produzir toxinas no alimento, em quantidade capaz de promover a intoxicação, reduz com a refrigeração abaixo de $14^{\circ} \mathrm{C}$.

No estabelecimento analisado o período de três horas de duração entre o abate e resfriamento da carcaça também pode ter dificultado multiplicação bacteriana de Salmonella sp e $S$. aureus. Segundo Borch et al. (1996), o tempo desde o início do abate até o resfriamento de uma carcaça suína geralmente é de 55 minutos, e até o início da evisceração de 20 minutos. Considerando que a fase lag da Salmonella sp e do $S$. aureus na superficie de carcaças em condições ambientais é de 3 horas e 4 horas, respectivamente, há a necessidade de um abate rápido e o emprego de refrigeração imediata para o controle desses patógenos (Borch et al. 1996).

A maior freqüência de Salmonella sp após a evisceração (ponto C, Quadro 1), mesmo que não tenha sido significativa, em comparação aos demais pontos, mostra que esta etapa realmente constitui um ponto que sinaliza para uma influência na contaminação da carcaça por enterobactérias. Da mesma forma, a maior freqüência de $S$. aureus no ponto B (Quadro 3), reforça a associação desse patógeno com as operações de abate, que envolvem muita manipulação, característica essa própria do estabelecimento estudado, com toalete entre os pontos A e B (Fig. 1). Esta situação deixa evidente a participação de Salmonella sp e de S. aureus como perigos microbiológicos e os quatro pontos estudados, principalmente a evisceração e a toalete, como PPCs que devem ser monitorados e controlados no sistema APPCC implantado em estabelecimentos de abate de suínos. Não foi evidenciada nenhuma predominância de um PCC sobre o outro, quanto à contaminação pelos referidos patógenos, uma vez que os resultados não revelaram aumentos significativos no número desses agentes patogênicos.
Algumas diferenças de resultados observadas nesta pesquisa quando comparadas com a literatura, em relação às variações da contaminação em diversos segmentos do processo de abate de suínos podem ser justificadas pela variação das condições de higiene operacional e pessoal, de equipamentos e das instalações vigentes em cada estabelecimento, revelando a complexidade das atividades de abate. Por isso, diferentes etapas podem se constituir em variados PCCs, em função da estrutura de abate de cada estabelecimento.

Considerando as peculiaridades estruturais do estabelecimento avaliado na presente pesquisa, alguns aspectos podem ser destacados para explicar a frequiência dos patógenos nos pontos avaliados, como o inicio das atividades há cerca de dois anos, o pleno funcionamento dos equipamentos, toalete semi-automática e o curto período de processamento devido a alta capacidade de abate. Acrescenta-se ainda que no estabelecimento estudado existia uma separação bem definida entre área suja e limpa, que também pode ter contribuído para a manutenção dos baixos números de contaminantes microbianos nas carcaças.

\section{REFERÊNCIAS}

Ayres M., Ayres Júnior M., Ayres D.L. \& Santos A S. 2000. BioEstat 2.0: aplicações estatísticas nas áreas das ciências biológicas e médicas. Sociedade Civil Mamirauá / CNPq, Belém/Brasília. 272p.

Bean N.H. \& Griffin P.M. 1990. Foodborne disease outbreaks in the United States, 1973- 1987: pathogens, vehicles and trends. J. Food Prot. 53:804817.

Berends B.R., Knapen F., Snijders J.M.A. \& Mossel D.A.A. 1997. Identification and quantification of risk factors regarding Salmonella spp. on pork carcasses. Int. J. Food Microbiol. 36(2/3):199-206.

Berends B.R., Knapen F., Mossel D.A.A., Burt S.A. \& Snijders J.M.A. 1998. Impact on human health of Salmonella spp. on pork in the Netherlands and the anticipated effects of some currently proposed control strategies. Int. J. Food Microbiol. 44(3):219-229.

Berends B.R., Urlings H.A.P., Snijders J.M.A. \& Knapen F. 1996. Identification and quantification of risk factors in animal management and transport regarding Salmonella spp. in pigs. Food. Microbiol. 30(1/2):37-53.

Biemuller G.W., Carpenter J.A. \& Reynolds A.E. 1973. Reduction of bacteria on pork carcasses. J. Food Sci. 38(2):261-263.

Borch E., Nesbakken T. \& Christensen, H. 1996. Hazard identification in swine slaughter with respect to foodborne bacteria. Int. J. Food Microbiol. 30(1/2):9-25.

Brasil 1997. Portaria no 451 de 19/09/97. Regulamento técnico. Princípios gerais para o estabelecimento de critérios e padrões microbiológicos para alimentos. Diário Oficial da União, Ministério da Saúde, Brasília. $17 p$.

Carr M.A., Thompson L.D., Miller M.F., Ramsey C.B. \& Kaster C.S. 1998. Chilling and trimming effects on the microbial populations of pork carcasses. J. Food Prot. 61(4):487-489.

Costa G.A., Hofer E., Costa M.D.M., Silva J.A.H., Santos J.V. \& Doria J.D. 1972. Isolation of Salmonella from lymph nodes of pigs slaughtered at the abattoir of Salvador, BA. Mem. Inst. Oswaldo Cruz. 70:417-431.

De Wit J.C. \& Kampelmacher E.H. 1981. Some aspects of microbial contamination of hands of workers in food industries. Zbl. Bakt. Hyg. I. Abt. Orig. B 172:390-400.

Epling L.K., Carpenter J.A. \& Blankenship L.C. 1993. Prevalence of Campylobacter spp. and Salmonella spp. on pork carcasses and the reduction effected by spraying with lactic acid. J. Food Prot. 56(6):536-537.

Gill C.O. \& Bryant J. 1993. The presence of Escherichia coli, Salmonella and 
Campylobacter in pig carcass dehairing equipment. Food Microbiol. 10(4):337-344.

Hald T., Wingstrand A., Swanenburg M., Altrock A.V., Limpitakis N. \& Thorberg B.M. 1999. Harvest epidemiology of Salmonella contamination in EU pig slaughterhouses. Proceedings of the 3rd International Symposium on the Epidemiology and Control of Salmonella in Pork, Washington, D.C., p. 273-276.

Hansson I.B. 2001. Microbiological meat quality in high- and low-capacity slaughterhouse in Sweden. J. Food Prot. 64(6):820-825.

ICMSF (International Commission on Microbiological Specification for Food). S.d. Microorganismos de los alimentos. Técnicas de análisis microbiológico. 2a ed. Zaragoza, Acribia, v. 1. 431p.

Kasbohrer A., Protz D., Helmuth R., Nockler K., Blaha T., Conraths F.J. \& Geue L. 2000. Salmonella in slaughter pigs of German origin: an epidemiological study. Eur. J. Epidemiol. 16(2):141-146.

Korsak N., Daube G., Ghafir Y., Chahed A., Jolly S. \& Vindevogel H. 1998. An efficient sampling technique used to detect four foodborne pathogens on pork and beef carcasses in nine belgian abattoirs. J. Food. Prot. 61(5):535-541.

Langenegger C.H., Alfinito J. \& Langenegger, J. 1983. Salmonelas isoladas de suínos de abate no estado do Pará. Pesq. Vet. Bras. 3(3):91-94.

Lázaro N.S., Tibana A. \& Hofer E. 1997. Salmonella spp. in healthy swine and in abattoir environments in Brazil. J. Food Prot. 60(9):1029-1033.

Letellier A., Messier S. \& Quessy S. 1999. Prevalence of Salmonella sp and Yersinia enterocolitica in finishing at Canadian abattoirs. J. Food Prot. 62(1):22-25

Mafu A.A., Higgins R., Nadeau M. \& Cousineau G. 1989. The incidence of Salmonella, Campylobacter, and Yersinia enterocolitica in swine carcasses and the slaughterhouse environment. J. Food Prot. 52(9):642-645.
Miller M.F., Carr M.A., Bawcom D.B., Ramsey C.B. \& Thompson L.D. 1997. Microbiol. of pork carcasses from pigs with differing origins and feed withdraw times. J. Food Prot. 60(3):242-245.

Oosterom J., Dekker R., Wilde G.J., Kempen-de-Troye F. \& Engels G.B. 1985. Prevalence of Campylobacter jejuni and Salmonella during pig slaughtering. Vet. Q. 7(1):31-34.

Rivas T., Vizcaíno J.A. \& Herrera F.J. 2000. Microbial contamination of carcasses and equipment from an Iberian pig slaughterhouse. J. Food Prot. 63(12):1670-1675.

Saide-Albornoz J.J., Knipe C.L., Murano E.A. \& Beran G.W. 1995. Contamination of pork carcasses during slaughter, fabrication, and chilled storage. J. Food Prot. 58(9):993-997.

Schlosser W., Hogue A., Ebel E., Rose B., Umholtz R., Ferris K. \& James, W. 2000. Analysis of Salmonella serotypes from selected carcasses and raw ground products sampled prior to implementation of the pathogen reduction; hazard analysis and critical point final rule in the US. Int. J. Food Microbiol. 58:107-111.

Schraft H., Kleinlein N. \& Untermann F. 1992. Contamination of pig hinquarters with Staphylococcus aureus. Int. J. Food Microbiol. 15(1/2):191194.

Swanenburg M., Urlings H.A.P., Snijders J.M.A., Keuzenkamp D.A \& Knapen, F. 2001. Salmonella in slaughter pigs: prevalence, serotypes and critical control points during slaughter in two slaughterhouses. Int. J. Food. Microbiol. 70(3):243-254.

Thorberg B.M. \& Engvall A. 2001. Incidence of Salmonella in five Swedish slaughterhouses. J. Food Prot. 64(4):542-545.

Zebral A.A. \& Freitas C.A. 1974. The occurrence of Salmonella in lymph nodes of seemingly normal swine slaughtered at abattoir of Santa Cruz, Rio de Janeiro. Mem. Inst. Oswaldo Cruz. 62:223-236. 